\title{
Ceftolozane/tazobactam for the treatment of complicated intra-abdominal and urinary tract infections: current perspectives and place in therapy
}

This article was published in the following Dove Press journal:

Infection and Drug Resistance

Laura Escolà-Vergé ${ }^{1,2}$

Carlos Pigrau ${ }^{1,2}$

Benito Almirante ${ }^{1,2}$

'Infectious Diseases Department, Hospital Universitari Vall d'Hebron, Medicine Department, Universitat Autònoma de Barcelona, Barcelona, Spain; ${ }^{2}$ Spanish Network for Research in Infectious Diseases (REIPI), Madrid, Spain
Correspondence: Benito Almirante Infectious Diseases Department, Hospital Universitari Vall d'Hebron, Paseo de la Vall d'Hebron, I19-129, Barcelona 08035, Spain

Email balmirante@vhebron.net

\begin{abstract}
The current prevalence of infections caused by multidrug-resistant (MDR) organisms is a global threat, and thus, the development of new antimicrobial agents with activity against these pathogens is a healthcare priority. Ceftolozane-tazobactam $(\mathrm{C} / \mathrm{T})$ is a new combination of a cephalosporin with a $\beta$-lactamase inhibitor that shows excellent in vitro activity against a broad spectrum of Enterobacteriaceae and Pseudomonas aeruginosa, including extended spectrum $\beta$ lactamase-producing (ESBL) strains and MDR or extensively drug-resistant (XDR) P. aeruginosa. In phase III randomized clinical trials, $\mathrm{C} / \mathrm{T}$ demonstrated similar efficacy to meropenem for the treatment of complicated intra-abdominal infections (cIAIs) and superior efficacy to levofloxacin for the treatment of complicated urinary tract infections (cUTIs), including pyelonephritis. The drug is generally safe and well tolerated and its PK/PD profile is very favorable. Observational studies with $\mathrm{C} / \mathrm{T}$ have revealed good efficacy for the treatment of different types of infection caused by MDR or XDR $P$. aeruginosa, including some that originated from the digestive or urinary tracts. The place of $\mathrm{C} / \mathrm{T}$ in therapy is not well defined, but its use could be recommended in a carbapenem-sparing approach for the treatment of infections caused by ESBL-producing strains or for the treatment of infections caused by P. aeruginosa if there are no other more favorable therapeutic options. Further clinical experience is needed to position this new antimicrobial drug for the empirical treatment of cIAIs or cUTIs. Keywords: ceftolozane-tazobactam, complicated intra-abdominal infections, complicated urinary tract infections, multidrug-resistant Pseudomonas aeruginosa
\end{abstract}

\section{Extent of complicated intra-abdominal and urinary tract infections in the era of bacterial multiresistance}

Complicated intra-abdominal infections (cIAIs) are defined as infections resulting from perforation of the gastrointestinal tract that extend into the peritoneal space and are associated with either abscess formation or peritonitis. ${ }^{1}$ This type of infection is usually polymicrobial and dominated by Gram-negative bacilli, particularly Enterobacteriaceae and Pseudomonas aeruginosa (found less frequently), and Gram-positive cocci and anaerobes have also been identified. ${ }^{2}$

These infections require immediate surgery combined with adequate antimicrobial treatment. The most widely used antimicrobial treatments are the combination of cefotaxime or ceftriaxone with metronidazole and monotherapy with amoxicillin/ clavulanic acid. However, the use of piperacillin/tazobactam and even carbapenems 
is becoming more common, even for community-acquired infections. The reason for this change is the unstoppable dissemination of extended spectrum $\beta$-lactamaseproducing (ESBL) enterobacteria. The global prevalence of class A ESBL-producing enterobacteria fecal colonization is $14 \%$, as inferred from a meta-analysis that included a population of 28,909 healthy people from five continents, and this prevalence shows an annual increase of 5.4\%. Africa and Asia are the continents with the highest prevalence, with rates of $45 \%$ and $15 \%$, respectively, and these are followed by Southern Europe (6\%), Central Europe (3\%), Northern Europe (4\%) and Northern America $(2 \%){ }^{2}$ In this context, the available antimicrobial treatment for cIAIs can be suboptimal, particularly in the countries and hospitals with the most unfavorable epidemiology.

The definition of complicated urinary tract infections (cUTIs) varies among studies, but the guidelines ${ }^{3,4}$ define cUTIs as urinary tract infections in patients with one or more of the following conditions: a) men, children, pregnant women or individuals aged $\geq 65$ years; $b$ ) women with functional or anatomical urinary tract abnormalities that cause obstruction or voiding disorders, any sort of ureteral derivation or foreign body (including indwelling bladder catheters), polycystic kidney disease, single kidney, recent (within 1 month) instrumentation or urinary tract surgery, diabetes mellitus, renal insufficiency or transplantation, other immunosuppressed states or underlying diseases (liver cirrhosis, active malignancy, congestive heart failure); and c) severe sepsis. The above conditions are frequently used to determine whether the patient needs to be admitted to the hospital, and some of these cUTIs are more likely to be related to multidrug-resistant (MDR) pathogens. However, the resistance rates in some of these populations, such as men, the elderly, patients with diabetes or acute urinary tract infection (UTI) following ureteral stone obstruction, might be similar to those of uncomplicated UTI.

The increased risk of UTIs due to MDR microorganisms is substantial in the group of healthcareassociated urinary tract infections (HCA-UTIs), which includes the following: a) patients who received intravenous therapy, wound care or specialized nursing care at home in the 30 days prior to the episode; b) patients who attended a hemodialysis center or received intravenous chemotherapy in the 30 days before the episode; c) patients who were hospitalized in an acute-care hospital for $\geq 2$ days in the 90 days before the current hospitalization; d) patients who reside in a nursing home or long-term care facility (LTCF); and e) patients who underwent an invasive urinary procedure in the 30 days before the episode or who have a long-term indwelling urethral catheter. This increased resistance has impacted the choice of empiric antibiotic therapy because higher failure rates with a poor outcome could be obtained if an adequate antibiotic therapy is not administered. ${ }^{3,4}$

Two recent studies ${ }^{5,6}$ found that the $P$. aeruginosa etiology and resistance rates in HCA-UTIs were higher than those in community-acquired urinary tract infections (CA-UTIs). In our experience the resistance rates of CAUTIs and HCA-UTIs among 607 patients with acute pyelonephritis (APN) were as follows: amoxicillin/clavulanic acid, $22.4 \%$ versus $53.2 \%$; cefuroxime, $7.7 \%$ versus $43.5 \%$; cefotaxime, $4.3 \%$ versus $32.6 \%$; ciprofloxacin, $22.8 \%$ versus $74.5 \%$; and cotrimoxazole, $34.5 \%$ versus $58.7 \%$. In both studies, previous antibiotic use (in the last 3 months) was also identified as an independent risk factor for antibiotic resistance.

\section{Current management of complicated intra-abdominal and urinary tract infections \\ Complicated intra-abdominal infections}

The management of cIAIs includes a combination of source control and adjunctive antibiotic therapy. Source control is defined as any procedure that eliminates infectious foci, control factors that promote ongoing infection, and correct or control anatomic derangements that restore normal physiologic function ${ }^{7}$ and can be achieved surgically and/or by percutaneous drainage of the associated abscess.

As mentioned above, due to the increasing resistance to aminopenicillins, third-generation cephalosporins, fluoroquinolones and aminoglycosides among Escherichia coli and the spread of ESBL-producing Enterobacteriaceae, antibiotic recommendations, in particularly those for highrisk and healthcare-associated infections, ${ }^{8,9}$ have changed because studies have shown that ineffective antimicrobial therapy is strongly associated with unfavorable outcomes in septic patients. ${ }^{10}$

For patients with mild-to-moderate community-acquired cIAIs, the current recommendation is to use narrower-spectrum antibiotics with activity against Enterobacteriaceae, aerobic streptococci, and anaerobes, and avoid 
antipseudomonal coverage. Cefotaxime or ceftriaxone plus metronidazole or ertapenem are some recommended agents for the initial therapy. As mentioned above, amoxicillin/ clavulanic acid and fluoroquinolones are no longer advisable as an empiric treatment due to frequent resistance, and clindamycin should also be avoided due to the increasing resistance rates among Bacteroides fragilis. ${ }^{1,11,12}$

Empirical treatment with broad-spectrum agents is needed for patients with high-risk community-acquired cIAIs. At present, piperacillin-tazobactam, doripenem, imipenem-cilastatin, meropenem, ceftazidime or cefepime plus metronidazole are some of the recommended regimens. ${ }^{1,11,12}$ For the empirical treatment of healthcare-associated cIAIs, the choice of antibiotic should be guided by regional epidemiological and resistance data. 11,12 ESBL-producer coverage is usually needed, and the use of piperacillin/tazobactam in this scenario remains controversial. ${ }^{13}$ Thus, carbapenems have been considered the preferred agents, but the spread of carbapenemase-producing Enterobacteriaceae (CPE) and MDR $P$. aeruginosa has become a global threat worldwide. Therefore, new antibiotics, such as ceftolozane/ tazobactam $(\mathrm{C} / \mathrm{T})$ and ceftazidime/avibactam in combination with metronidazole appear promising.

Finally, the tailoring of antimicrobial treatment once the results of susceptibility reports become available is essential, and limiting the length of antimicrobial therapy to four days in patients with adequate source control is also important. ${ }^{14}$ Patients showing ongoing signs of infection after five days of adequate antibiotic treatment should undergo a diagnostic investigation and be reassessed for a possible new source control intervention. ${ }^{1}$

\section{Complicated urinary tract infections}

According to the IDSA guidelines, ${ }^{4}$ the empiric antimicrobial therapy for APN should be based on local susceptibility antibiotic data. It has been recommended that antibiotics with a resistance rate higher than $10 \%$ should be avoided in empirical therapy. However, this recommendation is not based on clinical studies.

The mortality rates of CA-UTIs are low (1\%), and in our clinical practice, an inadequate empirical antibiotic is not associated with a worse outcome, particularly in patients without septic shock. ${ }^{5}$ Thus, when discussing a new local guideline for the treatment of cUTIs, the severity of the underlying infection and the risk of an MDR microorganism should be balanced with the initiation of an antibiotic with broad-spectrum coverage, such a carbapenem, because the overuse of carbapenems might increase the risk of infections due to $\mathrm{CPE} .^{3-6,15,16}$

Risk factors for ESBL-producing bacterial infections are previous colonization, recurrent UTIs, previous use of thirdgeneration cephalosporins or quinolones, healthcareassociated infections and recent travel to high-risk areas. In our setting, Germany and other countries with high resistance rates to amoxicillin, cotrimoxazole, amoxicillin/ clavulanic acid, and quinolones, a second- or thirdgeneration cephalosporin or an aminoglycoside are adequate initial options for non-severe patients without risk factors for ESBL-producers. ${ }^{3,5,6}$ Aztreonam, an aminoglycoside, a carbapenem, or intravenous fosfomycin could be used for allergic patients.

For more severe infections or patients with risk factors for ESBL-producing bacteria, a carbapenem or piperacillintazobactam may be used. ${ }^{17}$ Other options could be aminoglycosides or intravenous fosfomycin, although the experience with these antimicrobial agents is limited.

An antipseudomonal agent should be used for the treatment of nosocomial or health-care cUTIs because $P$. aeruginosa is the most commonly found pathogen (15\% of our HCA-UTIs). The choice of empirical agent should be based on local susceptibility data. In our setting, $25-35 \%$ of the isolated agents are resistant to piperacillintazobactam, ceftazidime, aztreonam, cefepime, fosfomycin, gentamicin, tobramycin or antipseudomonal carbapenem. Amikacin (which has the lowest resistance rates) should be included in the treatment of septic cases. C/T or ceftazidime-avibactam might be other alternatives, particularly for cases with previous MDR or extremely drugresistant (XDR) $P$. aeruginosa colonization. In countries with a high incidence and risk factors for carbapenemresistant microorganisms, ceftazidime-avibactam, aztreonam, aminoglycosides, fosfomycin, colistin or a combination with a carbapenem should be considered.

For patients with indwelling urinary devices and septic shock, antimicrobial coverage against multiresistant Grampositive microorganisms, such as methicillin-resistant Staphylococcus aureusand Enterococcus faecium, should be considered; however, a recent study that included consecutive adult (mainly elderly) patients with a chronic indwelling catheter-associated UTI and sepsis revealed that appropriate antibiotic treatment had no significant effect on short- and long-term survival or on the length of stay and length of febrile illness. The overall mortality was approximately $30 \%$, but the mortality rate of patients with an MDR Gram-negative infection and that of 
patients with enterococcal infection were $55 \%$ and only $8.6 \%$, respectively. ${ }^{18}$ These data suggest that enterococci likely have little impact on mortality.

\section{Spectrum and in vitro activity of ceftolozane/tazobactam}

\section{Chemistry and mode of action}

$\mathrm{C} / \mathrm{T}$ is a new combination of a novel semisynthetic antipseudomonal cephalosporin with a well-established $\beta$ lactamase inhibitor (2:1 ratio). ${ }^{19}$ The approved indications of $\mathrm{C} / \mathrm{T}$ are the treatment of cUTIs and the treatment of cIAIs when administered in combination with metronidazole, and it is currently investigated in phase III trials for the treatment of hospital-acquired pneumonia.

Ceftolozane is an oxyimino-aminothiazolyl cephalosporin that is structurally similar to ceftazidime but has a modified side chain that contributes to the stability of the drug in the presence of AmpC $\beta$-lactamases, prevents the hydrolysis of the $\beta$-lactam ring, and thus confers potent activity against $P$. aeruginosa. ${ }^{20,21}$ This cephalosporin exerts its bactericidal activity by binding to penicillinbinding proteins (PBPs) and causing cell death. ${ }^{21}$ Compared with ceftazidime, ceftolozane shows at least twofold higher potency in terms of minimum inhibitory concentration (MIC) and binding affinities for PBP1b, PBP1c, PBP2, and PBP3. ${ }^{21}$ Ceftolozane is not a substrate of the carbapenem-specific porin OprD or the efflux pumps found in P. aeruginosa. ${ }^{22}$ However, the ceftolozane activity can be affected by some other $\beta$-lactamases, such as ESBLs. Thus, it has been formulated in combination with tazobactam to broaden its antimicrobial activity. ${ }^{23}$ Tazobactam is a sulfone $\beta$-lactamase inhibitor that binds irreversibly to the active site of serine $\beta$-lactamases and thereby protects the $\beta$-lactam against hydrolysis. It inhibits most class A narrow-spectrum $\beta$-lactamases, ESBLs, and some class $\mathrm{C}$ enzymes and enhances the activity of ceftolozane against some ESBLproducing Enterobacteriaceae and anaerobes. ${ }^{24,25}$

\section{Spectrum and in vitro activity}

$\mathrm{C} / \mathrm{T}$ primarily shows in vitro activity against many aerobic Gram-negative bacilli, including most ESBL-producing E. coli (particularly TEM- and CTX-M-type ESBLs), but its potency against ESBL-producing $K$. pneumoniae is lower. $^{23,26,27}$ Several studies have tested the in vitro activity of $\mathrm{C} / \mathrm{T}$ against clinical isolates from intra-abdominal and urinary tract infections (Table 1). ${ }^{28-30} \mathrm{C} / \mathrm{T}$, amikacin, and meropenem are the antibiotics with the highest activity against Enterobacteriaceae. ${ }^{26,30} \mathrm{C} / \mathrm{T}$ is very active against E. coli $\left(\mathrm{MIC}_{50 / 90}, 0.25 / 0.5 \mathrm{mg} / \mathrm{L} ; 98.5-99.9 \%\right.$ inhibited at an MIC of $\leq 8 \mathrm{mg} / \mathrm{L}$ ), and many of the MDR ( $\mathrm{MIC}_{50 / 90}, 0.5 /$ $2->32 \mathrm{mg} / \mathrm{L})$ and ESBL-phenotype strains $\left(\mathrm{MIC}_{50 / 90}, 0.5 /\right.$ $2->32 \mathrm{mg} / \mathrm{L}$ ). It also showed activity against most $K$. pneumoniae strains $\left(\mathrm{MIC}_{50 / 90}, \quad 0.25 / 16 \mathrm{mg} / \mathrm{L}\right.$, $88.9-89.6 \%$ inhibited at an $\mathrm{MIC}$ of $\leq 8 \mathrm{mg} / \mathrm{L}$ ), but elevated MIC values were found for some ESBL-phenotype strains $\left(\mathrm{MIC}_{50 / 90}, 4-8 />32 \mathrm{mg} / \mathrm{L}\right)$ and MDR ( $\mathrm{MIC}_{50 / 90}, 16 />32 \mathrm{mg} /$ L). ${ }^{29} \mathrm{C} / \mathrm{T}$ was very active as well against other Enterobacteriaceae, such as Enterobacter spp. $\left(\mathrm{MIC}_{50 / 90}\right.$, $0.5 / 8 \mathrm{mg} / \mathrm{L}$ ), Citrobacter spp. ( $\mathrm{MIC}_{50 / 90}, 0.25 / 32 \mathrm{mg} / \mathrm{L}$ ), Serratia spp. $\left(\mathrm{MIC}_{50 / 90}, \quad 0.5 / 2 \mathrm{mg} / \mathrm{L}\right), \quad K . \quad$ oxytoca $\left(\mathrm{MIC}_{50 / 90}, 0.25 / 2 \mathrm{mg} / \mathrm{L}\right)$, Proteus mirabilis $\left(\mathrm{MIC}_{50 / 90}, 0.5 /\right.$ $0.5 \mathrm{mg} / \mathrm{L}$ ), and indole-positive Proteae $\left(\mathrm{MIC}_{50 / 90}, 0.25 /\right.$ $0.5 \mathrm{mg} / \mathrm{L}){ }^{29,30}$ However, C/T lacks activity against CPE $\left(\mathrm{MIC}_{50 / 90}, 32 />32 \mathrm{mg} / \mathrm{L}\right)^{30,31}$ because it has no activity against metallo- $\beta$-lactamases, K. pneumoniae carbapenemases, and class D enzymes. ${ }^{23}$

However, the standout quality of $\mathrm{C} / \mathrm{T}$ is its singular potency against $P$. aeruginosa. $\mathrm{C} / \mathrm{T}$ generally showed fourfold higher activity against $P$. aeruginosa compared with ceftazidime, ${ }^{28}$ and it was the most potent $\beta$-lactam agent and inhibited $>90 \%$ of isolates at an MIC of $<8 \mathrm{mg} / \mathrm{L}^{28,30}$ In addition, $\mathrm{C} / \mathrm{T}$ had activity against many MDR P. aeruginosa strains $\left(\mathrm{MIC}_{50 / 90}, 2-4 />32 \mathrm{mg} / \mathrm{L}\right)$, ceftazidime-nonsusceptible strains $\left(\mathrm{MIC}_{50 / 90}, 2-4 />32 \mathrm{mg} / \mathrm{L}\right)$, and meropenem-nonsusceptible strains ( $\mathrm{MIC}_{50 / 90}, 2 /$ $>32 \mathrm{mg} / \mathrm{L}) .{ }^{29}$ Only colistin was more active; specifically, colistin inhibited $99.5 \%$ of isolates. ${ }^{31}$ However, C/T has no in vitro activity against other nonfermenting bacteria such as Acinetobacter spp. or Stenotrophomonas spp.

In contrast, $\mathrm{C} / \mathrm{T}$ lacks activity against many Grampositive pathogens. Although it shows some in vitro activity against Streptococcus species, it has very limited activity against $S$. aureus and no anti-enterococcal activity. The activity of $\mathrm{C} / \mathrm{T}$ against anaerobic bacteria is very variable: it shows in vitro activity against Fusobacterium spp., adequate activity against $B$. fragilis and Prevotella, and low or no activity against other Bacteroides spp. and Clostridium spp. ${ }^{32}$ Based on this finding, metronidazole should be added to $\mathrm{C} / \mathrm{T}$ to ensure for anaerobic coverage in cIAIs. ${ }^{33-35}$

\section{Pharmacokinetics and pharmacodynamics of ceftolozane/tazobactam}

When ceftolozane is administered as a 1-h intravenous infusion at a dose of $1.5 \mathrm{~g}$ ( $1 \mathrm{~g}$ of ceftolozane and $0.5 \mathrm{~g}$ of Tazobactam), 
Table I In vitro activity of ceftolozane-tazobactam against clinical isolates from intra-abdominal and urinary tract infections

\begin{tabular}{|c|c|c|c|c|c|}
\hline Source & Pathogen & $\begin{array}{l}\text { Number of } \\
\text { isolates }\end{array}$ & $\begin{array}{l}\text { TOL/TAZ } \\
\text { MIC }_{50}(\mu g / m L ; \\
\text { range) }\end{array}$ & $\begin{array}{l}\text { TOL/TAZ } \\
\text { MIC } 90(\mu g / m L ; \\
\text { range) }\end{array}$ & TOL/TAZ S\%a \\
\hline $\begin{array}{l}\text { Aerobic Gram-negative } \\
\text { organisms isolated from } \\
\text { intra-abdominal and } \\
\text { urinary tract infections } \\
\text { in hospitals in Europe } \\
\text { and the USA }(2012)^{29}\end{array}$ & $\begin{array}{l}\text { Escherichia coli } \\
\text { MDR E. coli } \\
\text { K. pneumoniae } \\
\text { MDR K. pneumoniae } \\
\text { Enterobacter spp. } \\
\text { Citrobacter spp. } \\
\text { Proteus mirabilis } \\
\text { P. aeruginosa } \\
\text { MDR P. aeruginosa } \\
\text { XDR P. aeruginosa } \\
\text { CAZ-NS P. aeruginosa } \\
\text { MEM-NS P. aeruginosa }\end{array}$ & $\begin{array}{l}1,674 \\
85 \\
442 \\
78 \\
228 \\
113 \\
117 \\
327 \\
59 \\
43 \\
61 \\
77\end{array}$ & $\begin{array}{l}0.25 \\
0.5 \\
0.25 \\
16 \\
0.25-0.5 \\
0.25 \\
0.5 \\
0.5 \\
2-4 \\
4-8 \\
2-4 \\
2\end{array}$ & $\begin{array}{l}0.5 \\
2 \text { to }>32 \\
16 \\
>32 \\
4-8 \\
2 \\
0.5 \\
4 \\
>32 \\
>32 \\
>32 \\
>32\end{array}$ & $\begin{array}{l}98.5-99.9 \\
75-98.6 \\
88.9-89.6 \\
\text { NR } \\
\text { NR } \\
\text { NR } \\
\text { NR } \\
93.4-95.7 \\
65-73.7 \\
56.7-61.5 \\
60-80.8 \\
75.5-79.2\end{array}$ \\
\hline & Pathogen & $\begin{array}{l}\text { Number of } \\
\text { isolates }\end{array}$ & $\begin{array}{l}\text { TOL/TAZ } \\
\text { MIC }_{50}(\mu \mathrm{g} / \mathrm{mL})\end{array}$ & $\begin{array}{l}\text { TOL/TAZ } \\
\text { MIC }_{90}(\mu \mathrm{g} / \mathrm{mL})\end{array}$ & $\begin{array}{l}\text { TOL/TAZ S\% } \\
\text { (CLSI/EUCAST) }\end{array}$ \\
\hline $\begin{array}{l}\text { Enterobacteriaceae and } \\
\text { Pseudomonas aeruginosa } \\
\text { causing urinary tract and } \\
\text { intra-abdominal infec- } \\
\text { tions in Europe ( } 2012- \\
2015)^{30}\end{array}$ & $\begin{array}{l}\text { Enterobacteriaceae } \\
\text { ESBL non-CRE phenotype } \\
\text { Escherichia coli } \\
\text { ESBL non-CRE phenotype } \\
\text { K. pneumoniae } \\
\text { ESBL phenotype } \\
\text { ESBL non-CRE phenotype } \\
\text { Enterobacter spp. } \\
\text { Enterobacter cloacae } \\
\text { Citrobacter koseri } \\
\text { Citrobacter freundii } \\
\text { P. mirabilis } \\
\text { ESBL phenotype } \\
\text { Indole-positive Proteeae } \\
\text { Serratia sPp. } \\
\text { P. aeruginosa } \\
\text { CAZ-NS P. aeruginosa } \\
\text { MEM-NS P. aeruginosa } \\
\text { PIP/TAZ-NS P. aeruginosa }\end{array}$ & $\begin{array}{l}5,950 \\
906 \\
3,460 \\
559 \\
917 \\
373 \\
280 \\
432 \\
278 \\
101 \\
111 \\
368 \\
32 \\
237 \\
77 \\
603 \\
139 \\
126 \\
162\end{array}$ & $\begin{array}{l}0.25 \\
0.5 \\
0.25 \\
0.5 \\
0.25 \\
4 \\
1 \\
0.5 \\
0.5 \\
0.25 \\
0.25 \\
0.5 \\
1 \\
0.25 \\
0.5 \\
0.5 \\
4 \\
2 \\
2\end{array}$ & $\begin{array}{l}1 \\
8 \\
0.5 \\
2 \\
>32 \\
>32 \\
>32 \\
8 \\
16 \\
0.5 \\
8 \\
0.5 \\
8 \\
1 \\
2 \\
4 \\
>32 \\
>32 \\
>32\end{array}$ & $\begin{array}{l}93.5 / 91.3 \\
82.8 / 74.9 \\
98.8 / 98 \\
92.7 / 87.8 \\
79.3 / 75.8 \\
49.1 / 41.6 \\
65.4 / 55.4 \\
78 / 69.7 \\
76.6 / 70.1 \\
100 / 100 \\
79.3 / 78.4 \\
97.3 / 95.7 \\
71.9 / 56.2 \\
97.5 / 94.9 \\
98.7 / 88.3 \\
91.7 / 91.7 \\
65.5 / 65.5 \\
65.9 / 65.9 \\
70.4 / 70.4\end{array}$ \\
\hline
\end{tabular}

Notes: ${ }^{a}$ Percentage of isolates inhibited at an MIC of ceftolozane-tazobactam of $\leq 8 \mathrm{mg} / \mathrm{L}$. Adapted with permission from Sader HS, Farrell DJ, Flamm RK, Jones RN. Ceftolozane/tazobactam activity tested against aerobic Gram-negative organisms isolated from intra-abdominal and urinary tract infections in European and United States hospitals (2012). J Infect. 2014;69(3):266-277. Copyright (C) 2014 The British Infection Association. Published by Elsevier Ltd. All rights reserved. ${ }^{29}$ And from: Pfaller MA, Bassetti M, Duncan LR, Castanheira M. Ceftolozane/tazobactam activity against drug-resistant Enterobacteriaceae and Pseudomonas aeruginosacausing urinary tract and intraabdominal infections in Europe: report from an antimicrobial surveillance programme (2012-15). J Antimicrob Chemother. 2017;72(5): 1386-1395. (c) The Author 2017. Published by Oxford University Press on behalf of the British Society for Antimicrobial Chemotherapy. All rights reserved. ${ }^{30}$

Abbreviations: TOL/TAZ, ceftolozane-tazobactam; MIC, minimum inhibitory concentration; S, susceptible; MDR, multidrug-resistant; XDR, extensively drug-resistant; CAZ-NS, ceftazidime-non-susceptible; MEM-NS, meropenem-non-susceptible; ESBL, extended-spectrum $\beta$-lactamase; CRE, carbapenem-resistant Enterobacteriaceae; PIP/ TAZ-NS, piperacillin-tazobactam-non-susceptible.

including when it is administered at multiple doses, it exhibits dose-linear pharmacokinetics (PK), with a mean Cmax of $74 \mathrm{mg} / \mathrm{dL}$ (Table 2). ${ }^{19,36-39}$ Unlike piperacillin, which increases the tazobactam levels, the combination of ceftolozane with tazobactam does not affect the PK of tazobactam. The mean plasma half-life is approximately $2.3 \mathrm{~h}$ and the protein binding is approximately $20 \%$. The steady-state distribution volume (VD) of ceftolozane is approximately $14 \mathrm{~L}$, which is close to the average extracellular volume, which suggests that ceftolozane can reach its therapeutic levels at extracellular sites of infection. The VD might be increased in patients with obesity and infection. ${ }^{19}$ The plasma to epithelial 
Table 2 Pharmacokinetics of ceftolozane-tazobactam in healthy adults ${ }^{38,39}$

\begin{tabular}{|l|l|l|}
\hline $\begin{array}{l}\text { Antibiotic (I g ceftolo- } \\
\text { zane - 0.5 g tazobactam) }\end{array}$ & Ceftolozane & Tazobactam \\
\hline Cmax mg/dl & $58-92$ & $18.0-18.4$ \\
Plasma half-life (h) & $1.86-2.64$ & $1.0-1.1$ \\
Protein binding (\%) & $16-21$ & $30 \%$ \\
AUC (mg h/L) & $143-230$ & $24-25$ \\
Volume of distribution (L) & $13-17$ & 18.2 \\
Epithelial lining fluid (ELF) (\%) & $0.46-0.60$ & $44-46$ \\
ELF (mean mg/dL) & 21 & 8 \\
Urinary elimination (\%) & $97-100$ & $>80 \%$ \\
Hemodialysis removal & $>90 \%$ & - \\
\hline
\end{tabular}

Notes: Adapted from: Miller B, Hershberger E, Benziger D, Trinh M, Friedland I. Pharmacokinetics and safety of intravenous ceftolozane-tazobactam in healthy adult subjects following single and multiple ascending doses. Antimicrob Agents Chemother. 2012;56(6):3086-3091. Copyright (C) 2012, American Society for Microbiology. All Rights Reserved. ${ }^{38}$ And from: Ge Y, Whitehouse MJ, Friedland I, Talbot GH. Pharmacokinetics and safety of CXA-I0I, a new antipseudomonal cephalosporin, in healthy adult male and female subjects receiving single and multiple-dose intravenous infusions. Antimicrob Agents Chemother. 2010;54(8):3427-3431. Copyright (c) 2010, American Society for Microbiology. ${ }^{39}$

lining fluid penetration (ELF) of ceftolozane is approximately $50 \%$, with a $42 \%$ interindividual variability. ${ }^{40}$ To our knowledge, there are no data on biliary excretion.

Ceftolozane is mainly eliminated by renal excretion, and tazobactam is mainly eliminated by renal excretion and by an M1 metabolite (Table 2). Ceftolozane has a linear PK over the range of renal function, and dose adjustments are required for subjects who show creatinine clearance $\left(\mathrm{CL}_{\mathrm{Cr}}\right)<50 \mathrm{~mL} / \mathrm{min}^{36,37}$ Because approximately $90 \%$ of the drug is removed during hemodialysis, it should be administered after dialysis.

Similar to other cephalosporins, $\mathrm{C} / \mathrm{T}$ is bactericidal, and the pharmacodynamic (PD) parameter that best predicts the bacteriologic efficacy is the time above the MIC (T>MIC) for $40-50 \%$ of the dosing interval. ${ }^{36,37}$ Based on Monte Carlo simulation models the probabilities of target attainment (PTAs) with a C/T dose of $1.5 \mathrm{~g}$ every $8 \mathrm{~h}$ for $50 \% \mathrm{~T}>\mathrm{MIC}$ are $100 \%$ with an $\mathrm{MIC} \leq 4 \mathrm{mg} / \mathrm{L}$ and $90 \%$ with an $\mathrm{MIC}=8 \mathrm{mg} / \mathrm{L}$. For patients with pneumonia, and MIC values up to $8 \mathrm{mg} / \mathrm{L}$, the PTAs in ELF for $40 \%$ and $50 \% \mathrm{~T}>\mathrm{MIC}$ are $75 \%$ and $59 \%$, respectively, and for a dose of $3 \mathrm{~g}$ every $8 \mathrm{~h}$ these values increase to $96 \%$ and $88 \%$, respectively. Thus, it has been suggested that higher doses should be administered to patients with pneumonia. ${ }^{40}$

For patients with cUTIs or cIAIs, the conventional dose of $1.5 \mathrm{~g}$ every $8 \mathrm{~h}$ is used, but real-life studies for the treatment of XDR P. aeruginosa infections have used higher doses, particularly for patients with abscesses, due to the lower penetration of antibiotics at the site of the infection. ${ }^{41}$

Although the $\mathrm{VD}$ and $\mathrm{Cl}_{\mathrm{Cr}}$ might be different from that of healthy adults, a recent study of severely obese patients $\left(\right.$ BMI $>35 \mathrm{~kg} / \mathrm{m}^{2}$ ) achieved a PTA of bactericidal activity of $>90 \%$ at an MIC up to $8 \mathrm{mg} / \mathrm{L}$. Moreover, pivotal phase 3 studies on cUTIs and cIAIs revealed similar clinical outcomes in severely obese and nonobese patients, and thus, no drug adjustments are needed in these cases. ${ }^{42}$

The FDA-approved dose adjustments for $\mathrm{C} / \mathrm{T}$ for patients with renal failure (RF) are as follows: for a $\mathrm{Cl}_{\mathrm{Cr}}$ of $30-50 \mathrm{~mL} / \mathrm{min}, \quad 500 / 250 \mathrm{mg} / 8 \mathrm{~h}$; for a $\mathrm{Cl}_{\mathrm{Cr}}$ of $15-29 \mathrm{~mL} / \mathrm{min}, 250 / 125 \mathrm{mg} / 8 \mathrm{~h}$, and for end-stage renal disease (EERD), loading dose of 500/250 followed by $100 /$ $50 \mathrm{mg} / 8 \mathrm{~h} .{ }^{19}$ However, two randomized controlled trials (RCT) on cIAIs and cUTIs showed that the clinical outcome in patients with moderate RF, which was observed in approximately $6 \%$ of cases, was lower compared with that of patients with mild or no RF. ${ }^{43}$ Moreover, a recent study revealed that patients with EERD and renal-replacement therapy showed lower cure rates. ${ }^{44}$

In a recent review, that included $>10,000$ patients with different types of infections, approximately $20 \%$ of the patients with cUTIs or cIAIs had acute kidney failure (AKF), which resolved by $48 \mathrm{~h}$ in $>50 \%$ of the cases. ${ }^{45}$ These data suggest that in septic patients with AKF, renal clearance improvement might lead to lower antibiotic plasma levels which could partially explain the higher failure rates observed in cases with RF. Thus, close renal clearance monitoring is necessary in cases with AKF.

For patients on hemodialysis and difficult-to-treat infections, such as $P$. aeruginosa pneumonia, higher doses (a loading dose of C/T of $1.5 \mathrm{~g}$ followed by $300 \mathrm{mg} / 8 \mathrm{~h}$ ) have been administered. ${ }^{46}$ There are scarce data for critically ill patients on continuous hemofiltration. It has been suggested that a $\mathrm{C} / \mathrm{T}$ dose of $1.5 \mathrm{~g} / 8 \mathrm{~h}$ administered during an extendedinfusion time of $4 \mathrm{~h}$ might work. ${ }^{47}$

$\mathrm{C} / \mathrm{T}$ has a low potential for clinically relevant drug-drug interactions because it is not a substrate for CYP and is not transported by OAT1 and OAT3 enzymes. ${ }^{48}$

\section{Importance of inappropriate treatment in complicated intra-abdominal and urinary tract infections}

Severe sepsis and septic shock remain a significant public health concern. Although the associated mortality has 
decreased due to increased awareness and improved management, it remains high, and a value of approximately $20 \%$ was obtained in the most recent multicenter trials. ${ }^{49}$

In 2010, a Cochrane Review on patients with sepsis concluded that although there is some evidence supporting the early administration of antimicrobials for these patients, a strong recommendation cannot be provided given the lack of prospective trials. ${ }^{50}$ The Survival Sepsis Campaign (SSC) released their latest guidelines in 2012, which included statements emphasizing that in patients with septic shock (1B) or severe sepsis (1C) antibiotics should be administered within an hour of recognition. ${ }^{51} \mathrm{~A}$ recent systematic review of the available literature (2005-2015) concluded that patients with septic shock who received appropriate antimicrobial therapy within $1 \mathrm{~h}$ of recognition had the greatest benefit in mortality. ${ }^{49}$

In patients with severe sepsis or septic shock, the control of the infectious foci (for example, abscess drainage in intrabdominal infection or insertion of a pig-tail urinary tract catheter for ureter obstruction) also has an important impact on mortality. In this sense, in a large study that included 3,663 patients with severe sepsis admitted to the ICU, lower mortality ( $21.2 \%$ versus $25.1 \%$ ) was detected in those who underwent source control for the infectious foci. ${ }^{52}$

In UTIs, discordant antimicrobial therapy selected based on in vitro antimicrobial susceptibility test results does not always yield a poor clinical outcome of the nonbacteremic UTI, because urinary concentrations of most antimicrobial agents are much higher than those in blood. ${ }^{53}$ However, in community-acquired bacteremic APNs, discordant empirical therapy leads to a notably worse early clinical response and longer hospital stay than concordant therapy, even though it does not affect the overall mortality or clinical cure rates. ${ }^{54}$ Other studies have found that appropriate antibiotic therapy has no impact on mortality but reduces the hospital stay and costs. ${ }^{55,56}$ Most likely, appropriate antibiotic therapy has no impact on mortality because the death rates related to APN are low $(1 \%),{ }^{5}$ even in elderly febrile UTI patients with severe underlying conditions. ${ }^{18}$ However, in our experience with APN, significantly higher ( $8.5 \%$ versus $14.7 \%, p>0.01$ ) relapse rates are obtained if antibiotic therapy is not tailored based on available susceptibility data. ${ }^{5}$

An antimicrobial-based approach for the treatment of cIAIs always involves a delicate balance between the optimization of empirical therapy, which has been shown to improve clinical outcomes, in some situations, and the reduction of excessive antimicrobial use, which has been proven to increase the rate of emergence of antimicrobialresistant strains. In several reviews or guidelines, ${ }^{1,12}$ it has been suggested that antimicrobial therapy plays an important role in the management of cIAIs. In severe septic patients, an insufficient or otherwise inadequate antimicrobial regimen is one of the variables most strongly associated with an unfavorable outcome. To our knowledge, the impact of an adequate empirical antimicrobial therapy on conditions with low mortality, such as noncomplicated appendicitis and non-severe cholecystitis, has not been adequately studied when the patients are treated with early surgery, but in our opinion the place of antibiotic therapy is probably irrelevant, because mortality is very low, and the recommended postoperative duration of therapy is very short. Excessive antimicrobial use might contribute to the emergence and spread of drug-resistant microorganisms and increase the overall treatment costs. ${ }^{12}$

In the IDSA guidelines ${ }^{1}$ for IAI, the selection of the appropriate antimicrobial regimen is selected primarily based on the presence or absence of risk factors for potential failure. The populations of patients at high risk include those with severe anatomically unfavorable infections or healthcare-related infections. In the WSES guidelines, high-risk patients are those with cIAIs with a specific risk for antimicrobial-resistant bacteria and/ or a severe clinical IAI. ${ }^{57}$ In the worldwide CIAOW study on cIAIs ${ }^{58}$ which included 1,898 patients with an overall mortality of $10 \%$, the factors associated with a higher mortality were the presence of sepsis or septic shock, a health-care infection, colonic nondiverticular perforation, a postoperative infection, complicated diverticulitis, malignancy or immunosuppression, delayed surgery and, logically, ICU admission, but the study did not analyze the impact of adequate antibiotic. All these factors should be considered in the future when analyzing an appropriate antibiotic therapy.

Moreover, the appropriateness of an antibiotic therapy might also depend on the causative agents and the type of intrabdominal foci. A retrospective study revealed that the mortality of patients with $P$. aeruginosa of an intraabdominal non-hepatobiliary source who received inappropriate antibiotic therapy as higher than that of adequately treated patients. ${ }^{59}$ However, discordant antimicrobial therapy has no impact on the mortality of patients with hepatobiliary disease.

As in UTIs, the identifications of risk factors for ESBL-IAIs might be useful for selection of the initial antibiotic therapy. In recent studies in patients with bacteremia from an intrabdominal source, carbapenem therapy was associated with a lower mortality rate than that of piperacillin-tazobactam treatment. ${ }^{13}$ 
The influence of adequate antibiotic therapy on the incidence of postoperative surgical site infections has not been adequately studied. In a recent worldwide study of 567 patients with acute cholecystitis treated mainly with surgery, factors associated with the presence of MDR microorganisms (mainly ESBLproducing enterobacteria) were the presence of a healthcare infection and recent antibiotic therapy. However, factors associated with a poor outcome were the presence of diffuse peritonitis and an inadequate source control, but the inadequacy of the empiric antibiotic therapy had no influence on mortality. ${ }^{60}$

In conclusion, in cUTIs, due to its low rates of mortality, an appropriate antibiotic therapy seems to have little impact on the outcome mortality but has an impact on the clinical outcome, hospital stay and risk of relapse. In severe cIAIs, inadequate antibiotic therapy has an impact on the outcome, with the control of the infection source being essential. The impact of adequate empiric antibiotic therapy on less severe IAIs when treated early with surgery (cholecystectomy, appendicectomy) is less relevant.

\section{Ceftolozane/tazobactam in the treatment of complicated intra-abdominal infections Clinical trials}

A phase II prospective, double-blind, randomized and multicenter trial compared $\mathrm{C} / \mathrm{T}$ plus metronidazole to meropenem for the treatment of cIAIs. ${ }^{33}$ Hospitalized adult patients with cIAIs that required surgical intervention were randomized $2: 1$ to receive $\mathrm{C} / \mathrm{T}$ ( $1.5 \mathrm{~g}$ IV q8h) plus metronidazole (500 mg IV q8h) or meropenem (1 g IV q8h). Clinical response at the test-of-cure visit in the microbiologically modified intent-to-treat (mMITT) and microbiologically evaluable (ME) per-protocol populations was the primary endpoint. Eighty-two patients received $\mathrm{C} / \mathrm{T}$, and 39 patients received meropenem. Clinical cure was observed in $83.6 \%(51 / 61)$ of patients who received $\mathrm{C} / \mathrm{T}$ versus $96 \%(24 / 25)$ of patients in the meropenem arm (difference $-12.4 \%$; 95\% CI,-34.9-11.1\%) in the mMITT population, and in $88.7 \%(47 / 53)$ and $95.8 \%(23 / 24)$ of the patients who received $\mathrm{C} / \mathrm{T}$ and meropenem, respectively (difference $-7.1 \%$; $95 \% \mathrm{CI},-30.7 \%$ to $16.9 \%$ ), in the $\mathrm{ME}$ population. $^{33}$

The ASPECT-cIAIs (assessment of the safety profile and efficacy of $\mathrm{C} / \mathrm{T}$ in complicated intra-abdominal infections) combined two identical prospective, doubleblind, randomized, multicenter phase III clinical trials that compared $\mathrm{C} / \mathrm{T}$ plus metronidazole with meropenem for the treatment of cIAIs. Hospitalized adult patients with cIAIs that required surgical intervention were randomized $1: 1$ to receive $\mathrm{C} / \mathrm{T}$ ( $1.5 \mathrm{~g}$ IV q8h) plus metronidazole (500 mg IV q8h) or meropenem ( $1 \mathrm{~g} \mathrm{IV} \mathrm{q8h)}$ for 4-14 days. The $\mathrm{C} / \mathrm{T}$ dose for patients with $\mathrm{Cl}_{\mathrm{Cr}}$ of $30-50 \mathrm{~mL} /$ minute was reduced to $750 \mathrm{mg}$ every $8 \mathrm{~h}$, and the meropenem dose was reduced to $1 \mathrm{~g}$ every $12 \mathrm{~h}$. The study endpoints were to demonstrate statistical noninferiority in clinical cure rates in the mMITT and ME populations using a noninferiority margin of $10 \%$ at the test-of-cure (TOC) visit (24-32 days from the start of therapy). Of 993 patients that were randomized only $806(81.2 \%)$ met the criteria for the mMITT population. Statistical noninferiority was demonstrated in both populations. The clinical cure rates were $83 \%$ (323/ 389) for C/T plus metronidazole and $87.3 \%$ (364/417) for meropenem in the mMITT population (weighted difference, $-4.2 \%$; 95\% CI, $-8.91-0.54$ ), and $94.2 \%$ (259/275) for C/T plus metronidazole and $94.7 \%$ (304/ 321) for meropenem (weighted difference, -1.0 ; $95 \%$ CI, -4.52-2.59) in the ME population.

Most diagnoses were appendicular perforation or peri-appendicular abscess (43.3\%) and peritonitis was present in $>80 \%$ of both patient populations. The distribution of pathogens and the per-pathogen clinical cure rates were similar in both arms, and most infections in both populations were polymicrobial. Resistant bacteria were slightly represented but equally distributed: 29 ESBL-producing Enterobacteriaceae in each group (overall rate of $7.2 \%$ ), and three of the 52 isolated $P$. aeruginosa were resistant to three or more classes of antipseudomonal antibiotics. In patients with ESBLproducing Enterobacteriaceae, the clinical cure rate was 95.8\% (23/24) for C/T plus metronidazole and $88.5 \%$ (23/26) for meropenem, and clinical cure rates of $100 \%$ $(13 / 13)$ and $72.7 \%(8 / 11)$ were obtained in patients with CTX-M-14/15 ESBLs, respectively. The type and frequency of adverse events (AEs) was similar in both groups (44.0\% versus $42.7 \%$ ).

\section{Real-life clinical experience}

As mentioned above, $\mathrm{C} / \mathrm{T}$ has proven effective for the treatment of cIAIs, with a clinical success rate of more than $80 \%$ in RCTs, ${ }^{33,34}$ but MDR microorganisms were not very well represented, particularly MDR $P$. aeruginosa,for which 


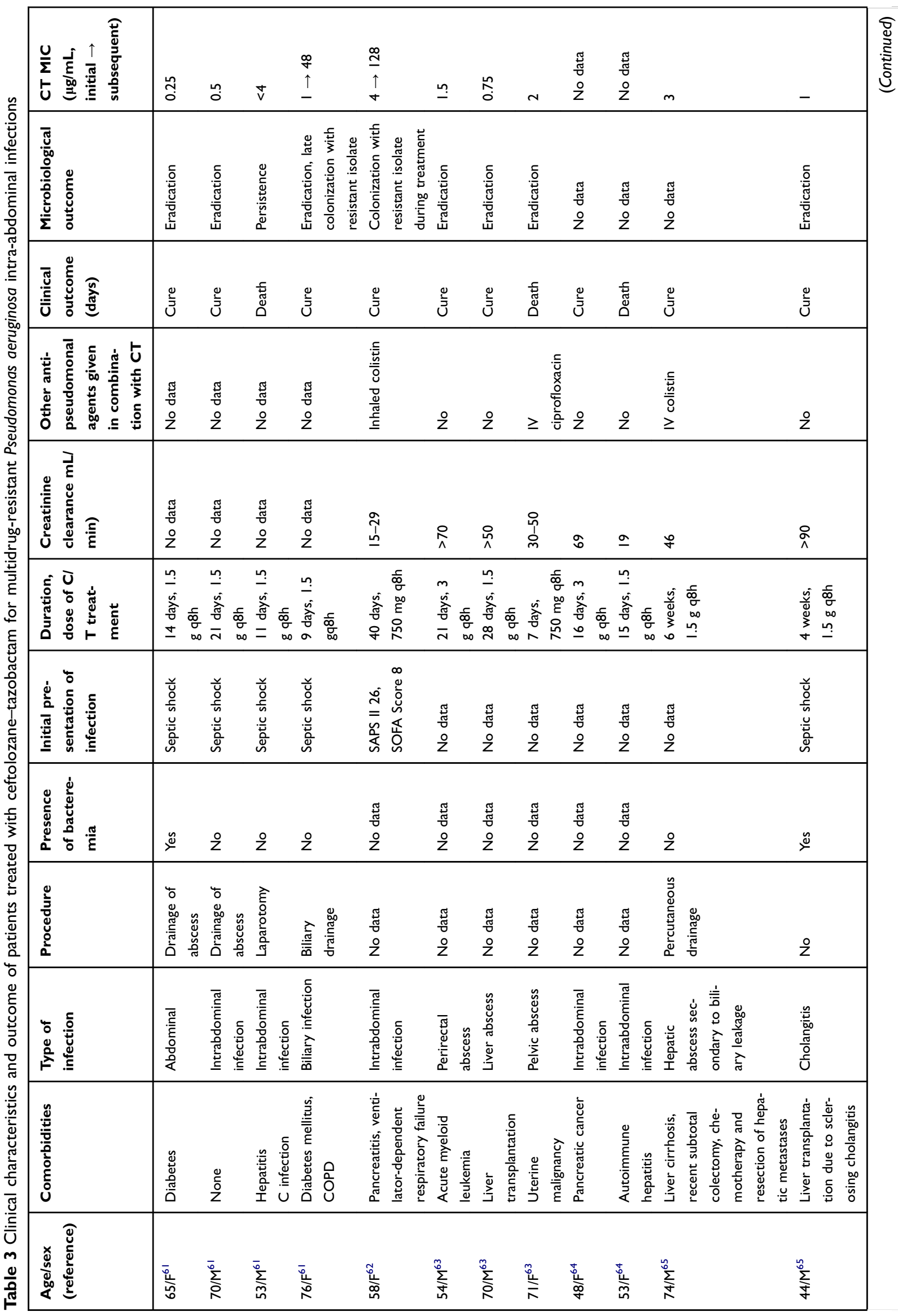




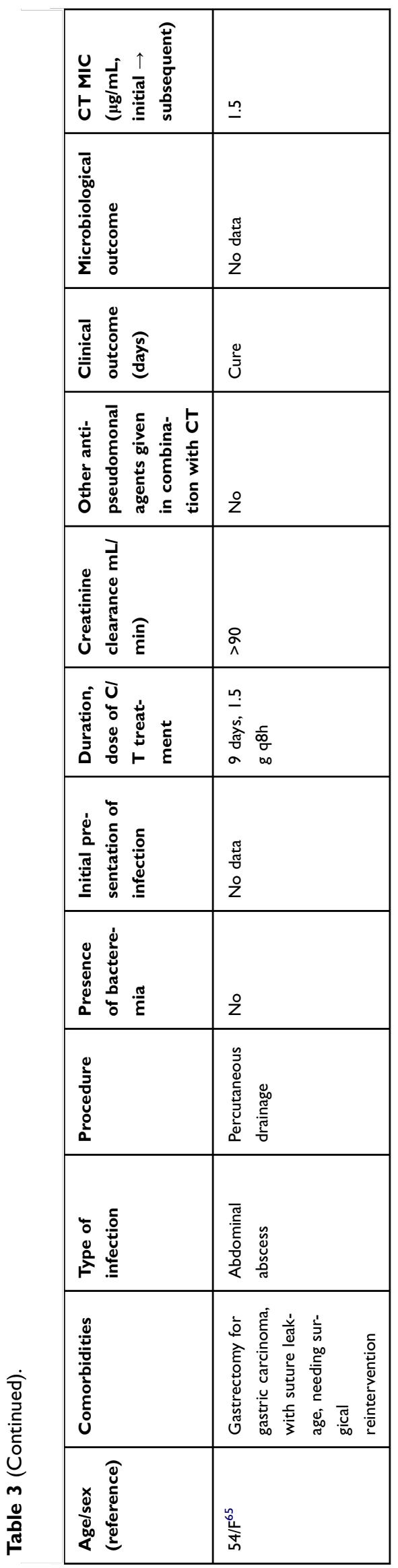

ceftolozane-tazobactam might be important. Therefore, several case reports and series have focused on analyzing the outcome of patients with cIAIs due to MDR $P$. aeruginosa who were treated with $\mathrm{C} / \mathrm{T}$ in daily practice.

Table 3 shows the clinical characteristics and outcomes of different cases of cIAIs due to MDR $P$. aeruginosa (the last five cases are due to XRD P. aeruginosa) that were treated with $\mathrm{C} / \mathrm{T} .{ }^{61-65}$ Overall, 10 of 13 (76.9\%) exhibited a good clinical outcome, and the other three died; in addition, in two (15.4\%) of the cases with favorable clinical outcome showed colonization with a C/T-resistant $P$. aeruginosa isolate. Each of two other unicenter observational studies of MDR P. aeruginosa infections treated with $\mathrm{C} / \mathrm{T}$ (one with 38 patients and the other with 58 patients) also included four cases of cIAIs, and in both studies three (75\%) of the cIAI patients exhibited a good clinical outcome. ${ }^{41,44}$

Two published multicenter retrospective studies also included some cases of cIAIs treated with $\mathrm{C} / \mathrm{T}$. In one study, which was performed in Italy, ${ }^{66} \mathrm{C} / \mathrm{T}$ was administered to 101 patients with diverse infections, including 13 (12.8\%) with cIAIs. Almost half of the $P$. aeruginosa strains included in this series were XDR (51\%), concomitant antibiotics were administered to $35 \%$ of patients, and high doses of $\mathrm{C} / \mathrm{T}$ (3 g every $8 \mathrm{~h}$ ) were given to $30.7 \%$ of patients, including two patients with cIAIs. The overall clinical success rate for cIAIs was $76.9 \%$ (10 of 13$)$. The other multicenter study, which was performed in the USA, ${ }^{67}$ included 205 patients, and 20 (9.8\%) of these patients had a cIAI. Thirty-day or inpatient mortality was observed in two $(10 \%)$ of the patients with cIAI, clinical success was seen in 15 (75\%) of the cIAI patients, and a microbiological cure was achieved in $18(90 \%)$.

The reasons for clinical failure in patients treated with $\mathrm{C} /$ $\mathrm{T}$ for $P$. aeruginosa infections have been analyzed. The risk factors associated with clinical failure that have been identified are a higher Simplified Acute Physiology Score-II (SAPS-II) score, ${ }^{62}$ sepsis, ${ }^{66}$ the administration of continuous renal replacement therapy during $\mathrm{C} / \mathrm{T}$ treatment, ${ }^{66}$ and an inadequate source control. ${ }^{41}$ In a unicenter study, a comparative univariate analysis evaluating risk factors for clinical failure found significant differences in disease severity, ventilator-dependent respiratory failure, XDR profile, high-risk clone ST175, negative control culture, and resistance development, but the multivariate analysis only identified ventilator-dependent respiratory failure as an independent risk factor. ${ }^{44}$ One study also found that the initiation of $\mathrm{C} / \mathrm{T}$ treatment within 4 days of culture collection is a significant predictor of survival, clinical success, and microbiological success. ${ }^{67}$ Concomitant anti-pseudomonal 
therapy or high doses of $\mathrm{C} / \mathrm{T}$ have not been identified as significant risk factors.

Another issue of concern is the selection of $\mathrm{C} / \mathrm{T}$-resistant strains due to mutations or overexpression in the resident AmpC $\beta$-lactamase during therapy, ${ }^{44}$ which has been observed in some cases of intraabdominal infections, ${ }^{41,61,62}$ particularly in those with inadequate source control. ${ }^{41}$

\section{Ceftolozane/tazobactam in the treatment of complicated urinary tract infections \\ Clinical trials}

The evidence for the efficacy of $\mathrm{C} / \mathrm{T}$ in cUTIs is based on the ASPECT-cUTI phase III trial, which was a prospective randomized, double-blind, double-dummy-controlled noninferiority trial undertaken in 135 centers worldwide. ${ }^{68}$ This trial included 1,083 hospitalized patients with clinical evidence of APN (82\%) or complicated lower UTI (18\%), defined by symptoms of acute cystitis plus one of the following: obstructive uropathy, indwelling urinary catheter or anatomical urogenital tract abnormality. Patients with severe progressive disease or septic shock, immunosuppressed patients, patients with severe renal failure $\left(\mathrm{Cl}_{\mathrm{Cr}}\right.$ $<30 \mathrm{ml} / \mathrm{min}$ ), patients with an infection that the investigator determined would require more than 7 days of therapy and patients who were not expected to survive 5 weeks were excluded. Only $7.8 \%$ of the patients had bacteremia. The infection was monomicrobial in $97 \%$ of the infections, E. coli was isolated in $79 \%$ of the cases, $14.8 \%$ of the patients had ESBL-producing Enterobacteriaceae, and only $2.9 \%$ of the infections were due to $P$. aeruginosa. The participants were randomized $1: 1$ to receive $\mathrm{C} / \mathrm{T}$ at 1.5 $\mathrm{g} / 8 \mathrm{~h}(\mathrm{n}=543)$ or levofloxacin at $750 \mathrm{mg}(\mathrm{n}=540)$ daily for 7 days. Of note, approximately $25 \%$ of the isolated pathogens were resistant to quinolones, and $2.7 \%$ to $\mathrm{C} / \mathrm{T}$.

Based on the composite cure outcome, which included clinical cure and microbiological eradication at 5-9 days after the last dose, $\mathrm{C} / \mathrm{T}$ was superior to levofloxacin in both the mMITT analysis (77\% versus $68 \%$ ) and the per-protocol analysis $(83 \%$ versus $75 \%)$. However, if only the patients with susceptible pathogens were analyzed, the outcomes were similar. As expected for ESBL-producing E. coli infections, higher microbiological cure rates were obtained with C/T [27/36 (75\%) versus 18/36 (50\%)] due to the high resistance rates to fluoroquinolones. For $P$. aeruginosa infections, the microbiological eradication rates obtained with $\mathrm{C} / \mathrm{T}$ and levofloxacin were $86 \%(6 / 7)$ and $58 \%$ (7/12), respectively. Based on these data, the clinical and microbiological efficacy of $\mathrm{C} / \mathrm{T}$ in MDR pathogens, which is one of the main indications for this drug, is insufficient because the efficacy of $\mathrm{C} / \mathrm{T}$ for ESBL infections has not been compared with the gold-standard antibiotic therapy, carbapenems, and patients with XDR $P$. aeruginosa infections were not included. In addition, only a few patients had severe infections, because bacteremia was uncommon. ${ }^{69}$

\section{Real-life clinical experience}

Most of the real-life published clinical experience on $\mathrm{C} / \mathrm{T}$ involves the treatment of MDR $P$. aeruginosa cUTIs. The published studies are case reports and small series of different types of MDR or XDR P. aeruginosa that include cases of cUTIs. ${ }^{41,62}$ Among these studies, the overall clinical efficacy was approximately $70 \%$, and $30-50 \%$ of the cases were treated with high doses of $\mathrm{C} / \mathrm{T}$. In our limited experience with patients with $P$. aeruginosa, patients with cUTI are usually treated with low $\mathrm{C} / \mathrm{T}$ doses (only one case with a prostatic abscess received high $\mathrm{C} / \mathrm{T}$ doses) ${ }^{41}$

In a study that included 58 patients (cUTI was the second type of treated infection), 8 of 10 patients with cUTI were cured. ${ }^{44}$ In another study that included 23 patients, among which seven had a cUTI (all were treated with conventional $\mathrm{C} / \mathrm{T}$ doses), only one showed clinical failure. ${ }^{65}$ Furthermore, in four studies that included a limited number of cases of cUTIs, none of the five included cases treated with low doses of $\mathrm{C} / \mathrm{T}$ showed clinical failure. ${ }^{61-64} \mathrm{~A}$ recent nationwide multicenter Italian study ${ }^{66}$ with 101 patients treated with $\mathrm{C} / \mathrm{T}$ for serious $P$. aeruginosa infections showed clinical failure in only one of $14(7.1 \%)$ patients with a cUTI. Overall, $30 \%$ of the cases were treated with high doses, but the dose to patients with a UTI was not specified. In the largest series, which included 205 patients with MDR Pseudomonas infection treated with $\mathrm{C} / \mathrm{T}$, the overall clinical and microbiological cure rates were $73.7 \%$ and $70.7 \%$, respectively, and those for patients with cUTIs were $89 \%$ (22/25) (89\%) and $89 \%(22 / 25)$, respectively. ${ }^{67}$

In summary, $49 / 57$ (86\%) of the cases with MDR P. aeruginosa cUTIs treated with $\mathrm{C} / \mathrm{T}$, usually with conventional doses (when specified), were cured, and this percentage is higher than the overall cure rate. In these studies patients with severe infections were included, because a significant percentage had bacteremia, and some patients had undergone solid organ or hematopoietic stem cell transplantation, had EERD and/or were admitted to the ICU. 


\section{Safety and tolerability of ceftolozane/tazobactam}

$\mathrm{C} / \mathrm{T}$ has a safety and tolerability profile similar to that of any other cephalosporin, as demonstrated by RCTs, which showed a percentage of AEs ranging from $35 \%$ to $50 \%$ [overall 438 AEs over 1,097 (39.9\%) patients treated with $\mathrm{C} / \mathrm{T}]$ and no significant differences with respect to their comparators. Between $3 \%$ and $17 \%$ of the patients presented severe adverse events (SAEs), although only three cases of Clostridium difficile infection were considered to be related to $\mathrm{C} / \mathrm{T}$. In the RCTs, no drug-related death was reported, and the most frequently reported AEs (with an incidence greater than 5\% in either indication) experienced by the patients treated with $\mathrm{C} / \mathrm{T}$ were nausea, headache, diarrhea, and pyrexia. ${ }^{33,34,68}$

In a postmarketing safety evaluation, seven cases of medication errors were reported to the FDA: these patients were administered a dose of $\mathrm{C} / \mathrm{T}$ that was $50 \%$ higher than the prescribed dose and experienced no AEs related to the medication error. ${ }^{70}$ Similarly, a multicenter, retrospective study of patients with carbapenem-resistant $P$. aeruginosa infections who were treated with $\mathrm{C} / \mathrm{T}$ ranging from $375 \mathrm{mg}$ to $3,000 \mathrm{mg}$ every $8 \mathrm{~h}$ for 5-27 days observed only two AEs (self-limited diarrhea and peripheral eosinophilia with eosinophiluria possibly due to interstitial nephritis), which resolved after the drug was stopped..$^{63}$ In a retrospective series of 38 patients with XDR $P$. aeruginosa infections treated with $\mathrm{C} / \mathrm{T}$ for 15.5 days (range of 3-62 days), $60.5 \%$ of the patients were administered doses of $3 \mathrm{~g}$ every $8 \mathrm{~h}$, and no AEs that forced the withdrawal of the antibiotic were observed. ${ }^{41}$

In summary, $\mathrm{C} / \mathrm{T}$ is a cephalosporin with a safety profile and tolerability similar to those of the remaining cephalosporins and can be administered to patients with cIAIs or cUTIs, and in particular, $\mathrm{C} / \mathrm{T}$ can be used, if necessary, at doses of up to $3 \mathrm{~g}$ every $8 \mathrm{~h}$ for a prolonged time (at least for 4 weeks).

\section{Conclusions and place in therapy}

$\mathrm{C} / \mathrm{T}$ is a cephalosporin with activity against most ESBLproducing Gram-negative rods and against MDR or XDR P. aeruginosa. Different published RCTs have reported the efficacy and safety profile for the treatment of cIAIs and cUTIs, and the results show that the drug has a favorable PK/ $\mathrm{PD}$ profile. The use of $\mathrm{C} / \mathrm{T}$ for the treatment of these infections should be considered in two clinical situations: as a potential alternative therapy to carbapenems in a carbapenem-sparing strategy, or for the treatment of infections caused by MDR or XDR P. aeruginosa.
In the first clinical situation, the use of $\mathrm{C} / \mathrm{T}$ for the treatment of ESBL-producing Gram-negative rod infections has been proposed for the recovery of carbapenem activity in a given health institution. It has been well demonstrated that the overuse of carbapenems can condition the appearance and dissemination of carbapenem-producing Enterobacteriaceae (CPE), which would significantly limit the potential use of these drugs. The reduction in the use of carbapenems is associated with a decrease in the frequency of CPE infections. In centers where ESBL-producing Gram-negative rod infections are endemic, a carbapenemsparing strategy (in either first-line therapy or de-escalation therapy) could be effective in preventing the appearance and dissemination of CPE. The recently published results of the MERINO study ${ }^{13}$ demonstrate the superiority of a carbapenem regimen over piperacillin-tazobactam for the treatment of infections caused by ceftriaxone-resistant E. coli or K. pneumoniae, and thus this therapeutic alternative should not be used in a carbapenem-sparing strategy. However, the results of the MERINO study could have been subject to numerous biases, both in the selection of patients, in the choice of the primary outcome, in the inclusion of patients from countries with different profiles and rates of antimicrobial resistance, and in the manner of administration of piperacillin-tazobactam. Therefore, its conclusions should be considered with caution.

Although there is no relevant clinical information, the stability of $\mathrm{C} / \mathrm{T}$ against $\mathrm{AmpC}$ beta-lactamases would allow its alternative use to carbapenems for the treatment of infections caused by SPACE organisms (Serratia, Providencia, Acinetobacter, Citrobacter, Enterobacter).

$\mathrm{C} / \mathrm{T}$ maintains its activity against $P$. aeruginosa species with multiple resistance mechanisms (efflux pumps, reduction uptake through porin channels, or modification of penicillin-binding proteins). Several observational studies have found that $\mathrm{C} / \mathrm{T}$ can be an effective therapy for the treatment of serious infections caused by MDR or XDR P. aeruginosa. In particular, when administered at an adequate dose (usually up to $3 \mathrm{~g}$ every 8 h), C/T can act on the source of the infection and the MIC value for $\mathrm{C} / \mathrm{T}$ does not exceed $4 \mathrm{mg} / \mathrm{L}$. C/T therapy for these serious infections provides a clinical success rate (in-hospital survival plus resolution of signs and symptoms) of approximately 75\%. Although the published experience in the treatment of cIAIs or cUTIs produced by MDR or XDR $P$. aeruginosa is very limited, the absence of effective therapeutic alternatives with an acceptable safety profile would make $\mathrm{C} /$ 
$\mathrm{T}$ a first-line therapeutic option for these infections. Therefore, $\mathrm{C} / \mathrm{T}$ should be routinely tested against every Gram-negative rod, and particularly against MDR or XDR $P$. aeruginosa.

\section{Acknowledgments}

The authors are funded by the Plan Nacional de I+D+I 2013-2016 and the Instituto de Salud Carlos III, Spain [REIPI RD16/0016/0003]. We would like to acknowledge the professional manuscript services of Nature Publishing Group Language Editing.

\section{Disclosure}

The authors have no other relevant affiliations or financial involvement with any organization or entity with a financial interest in or financial conflict with the subject matter or materials discussed in the manuscript apart from those disclosed.

\section{References}

1. Solomkin JS, Mazuski JE, Bradley JS, et al. Diagnosis and management of complicated intra-abdominal infection in adults and children: guidelines by the Surgical Infection Society and the Infectious Diseases Society of America. Clin Infect Dis. 2010;50(2):133-164. doi: $10.1086 / 649554$

2. Babinchak T, Badal R, Hoban D, et al. Trends in susceptibility of selected gram-negative bacilli isolated from intra-abdominal infections in North America: SMART 2005-2010. Diagn Microbiol Infect Dis. 2013;76(3):379-381. doi:10.1016/j.diagmicrobio.2013.02.031

3. de Cueto M, Aliaga L, Alós J-I, et al. Executive summary of the diagnosis and treatment of urinary tract infection: guidelines of the Spanish Society of Clinical Microbiology and Infectious Diseases (SEIMC). Enferm Infecc Microbiol Clin. 2017;35(5):314-320. doi:10.1016/j.eimc.2016.11.005

4. Gupta K, Hooton TM, Naber KG, et al. International clinical practice guidelines for the treatment of acute uncomplicated cystitis and pyelonephritis in women: a 2010 update by the Infectious Diseases Society of America and the European Society for Microbiology and Infectious Diseases. Clin Infect Dis. 2011;52(5):e103-e120. doi:10.1093/cid/ciq257

5. Bosch-Nicolau P, Falcó V, Viñado B, et al. A cohort study of risk factors that influence empirical treatment of patients with acute pyelonephritis. Antimicrob Agents Chemother. 2017;61(12). doi:10.1128/AAC.01317-17

6. Bischoff S, Walter T, Gerigk M, Ebert M, Vogelmann R. Empiric antibiotic therapy in urinary tract infection in patients with risk factors for antibiotic resistance in a German emergency department. $B M C$ Infect Dis. 2018;18. doi:10.1186/s12879-018-2960-9

7. Marshall JC, Maier RV, Jimenez M, Dellinger EP. Source control in the management of severe sepsis and septic shock: an evidence-based review. Crit Care Med. 2004;32(11 Suppl):S513-S526.

8. Morrissey I, Hackel M, Badal R, Bouchillon S, Hawser S, Biedenbach D. A review of ten years of the study for monitoring antimicrobial resistance trends (SMART) from 2002 to 2011. Pharmaceuticals. 2013;6(11):1335-1346. doi:10.3390/ph6111335
9. Hackel MA, Badal RE, Bouchillon SK, Biedenbach DJ, Hoban DJ. Resistance rates of intra-abdominal isolates from intensive care units and non-intensive care units in the United States: the study for monitoring antimicrobial resistance trends 2010-2012. Surg Infect (Larchmt). 2015;16(3):298-304. doi:10.1089/sur.2014.060

10. Paul M, Shani V, Muchtar E, Kariv G, Robenshtok E, Leibovici L. Systematic review and meta-analysis of the efficacy of appropriate empiric antibiotic therapy for sepsis. Antimicrob Agents Chemother. 2010;54(11):4851-4863. doi:10.1128/AAC.00627-10

11. Mazuski JE, Tessier JM, May AK, et al. The Surgical Infection Society revised guidelines on the management of intra-abdominal infection. Surg Infect (Larchmt). 2017;18(1):1-76. doi:10.1089/sur.2016.261

12. Sartelli M, Chichom-Mefire A, Labricciosa FM, et al. The management of intra-abdominal infections from a global perspective: 2017 WSES guidelines for management of intra-abdominal infections. World J Emerg Surg. 2017;12(1). doi:10.1186/s13017-017-0141-6

13. Harris PNA, Tambyah PA, Lye DC, et al. Effect of piperacillin-tazobactam vs meropenem on 30-day mortality for patients with E. coli or Klebsiella pneumoniae bloodstream infection and ceftriaxone resistance: a randomized clinical trial. JAMA. 2018;320(10):984-994. doi:10.1001/jama.2018.12163

14. Sawyer RG, Claridge JA, Nathens AB, et al. Trial of short-course antimicrobial therapy for intraabdominal infection. $N$ Engl $J$ Med. 2015;372(21):1996-2005. doi:10.1056/NEJMoa1411162

15. Bader MS, Loeb M, Brooks AA. An update on the management of urinary tract infections in the era of antimicrobial resistance. Postgrad Med. 2017;129(2):242-258. doi:10.1080/00325481.2017.1246055

16. Hawkey PM, Warren RE, Livermore DM, et al. Treatment of infections caused by multidrug-resistant Gram-negative bacteria: report of the British Society for Antimicrobial Chemotherapy/Healthcare Infection Society/British Infection Association Joint Working Party. J Antimicrob Chemother. 2018;73(suppl_3):iii2-iii78. doi:10.1093/jac/dky027

17. Rodríguez-Baño J, Navarro MD, Retamar P, Picón E, Pascual Á; Extended-Spectrum Beta-Lactamases-red Española de Investigación en Patología Infecciosa/Grupo de Estudio de Infección Hospitalaria Group. $\beta$-Lactam $/ \beta$-lactam inhibitor combinations for the treatment of bacteremia due to extended-spectrum $\beta$-lactamase-producing Escherichia coli: a post hoc analysis of prospective cohorts. Clin Infect Dis. 2012;54(2):167-174. doi:10.1093/cid/cir790

18. Babich T, Zusman O, Elbaz M, et al. Empirical antibiotic treatment does not improve outcomes in catheter-associated urinary tract infection: prospective cohort study. Clin Infect Dis. 2017;65 (11):1799-1805. doi:10.1093/cid/cix680

19. van Duin D, Bonomo RA. Ceftazidime/avibactam and ceftolozane/ tazobactam: second-generation $\beta$-lactam/ $\beta$-lactamase inhibitor combinations. Clin Infect Dis. 2016;63(2):234-241. doi:10.1093/cid/ciw243

20. Murano K, Yamanaka T, Toda A, et al. Structural requirements for the stability of novel cephalosporins to AmpC $\beta$-lactamase based on 3Dstructure. Bioorg Med Chem. 2008;16(5):2261-2275. doi:10.1016/j. bmc.2007.11.074

21. Moya B, Zamorano L, Juan C, Ge Y, Oliver A. Affinity of the new cephalosporin cxa-101 to penicillin-binding proteins of Pseudomonas aeruginosa. Antimicrob Agents Chemother. 2010;54(9):3933-3937. doi:10.1128/AAC.00296-10

22. Moya B, Dötsch A, Juan C, et al. $\beta$-Lactam resistance response triggered by inactivation of a nonessential penicillin-binding protein. Ausubel FM, ed. PLoS Pathog. 2009;5(3):e1000353. doi:10.1371/journal.ppat.1000353

23. Livermore DM, Mushtaq S, Ge Y. Chequerboard titration of cephalosporin CXA-101 (FR264205) and tazobactam versus beta-lactamase-producing Enterobacteriaceae. J Antimicrob Chemother. 2010;65(9):1972-1974. doi:10.1093/jac/dkq248

24. Cluck D, Lewis P, Stayer B, Spivey J, Moorman J. Ceftolozanetazobactam: a new-generation cephalosporin. Am J Health Syst Pharm. 2015;72(24):2135-2146. doi:10.2146/ajhp150049 
25. Bush K, Macalintal C, Rasmussen BA, Lee VJ, Yang Y. Kinetic interactions of tazobactam with b-lactamases from all major structural classes. Antimicrob Agents Chemother. 1993;37:8. doi:10.1128/ AAC.37.4.851

26. Farrell DJ, Flamm RK, Sader HS, Jones RN. Antimicrobial activity of ceftolozane-tazobactam tested against Enterobacteriaceae and Pseudomonas aeruginosa with various resistance patterns isolated in U.S. hospitals (2011-2012). Antimicrob Agents Chemother. 2013;57 (12):6305-6310. doi:10.1128/AAC.01802-13

27. Titelman E, Karlsson IM, Ge Y, Giske CG. In vitro activity of CXA-101 plus tazobactam (CXA-201) against CTX-M-14- and CTX-M-15-producing Escherichia coli and Klebsiella pneumoniae. Diagn Microbiol Infect Dis. 2011;70(1):137-141. doi:10.1016/j. diagmicrobio.2011.02.004

28. Sader HS, Farrell DJ, Castanheira M, Flamm RK, Jones RN. Antimicrobial activity of ceftolozane/tazobactam tested against Pseudomonas aeruginosa and Enterobacteriaceae with various resistance patterns isolated in European hospitals (2011-12). J Antimicrob Chemother. 2014;69(10):2713-2722. doi:10.1093/jac/dku184

29. Sader HS, Farrell DJ, Flamm RK, Jones RN. Ceftolozane/tazobactam activity tested against aerobic Gram-negative organisms isolated from intra-abdominal and urinary tract infections in European and United States hospitals (2012). J Infect. 2014;69(3):266-277. doi:10.1016/j. jinf.2014.04.004

30. Pfaller MA, Bassetti M, Duncan LR, Castanheira M. Ceftolozane/ tazobactam activity against drug-resistant Enterobacteriaceae and Pseudomonas aeruginosa causing urinary tract and intraabdominal infections in Europe: report from an antimicrobial surveillance programme (2012-15). J Antimicrob Chemother. 2017;72(5):1386-1395. doi: $10.1093 / \mathrm{jac} / \mathrm{dkx} 009$

31. Shortridge D, Pfaller MA, Castanheira M, Flamm RK. Antimicrobial activity of ceftolozane-tazobactam tested against Enterobacteriaceae and Pseudomonas aeruginosa with various resistance patterns isolated in U.S. Hospitals (2013-2016) as part of the surveillance program: program to assess ceftolozane-tazobactam susceptibility. Microb Drug Resist. 2018;24(5):563-577. doi:10.1089/mdr.2017.0266

32. Snydman DR, McDermott LA, Jacobus NV. Activity of ceftolozane-tazobactam against a broad spectrum of recent clinical anaerobic isolates. Antimicrob Agents Chemother. 2014;58 (2):1218-1223. doi:10.1128/AAC.02253-13

33. Lucasti C, Hershberger E, Miller B, et al. Multicenter, double-blind, randomized, phase ii trial to assess the safety and efficacy of ceftolozane-tazobactam plus metronidazole compared with meropenem in adult patients with complicated intra-abdominal infections. Antimicrob Agents Chemother. 2014;58(9):5350-5357. doi:10.1128/AAC.00049-14

34. Solomkin J, Hershberger E, Miller B, et al. Ceftolozane/tazobactam plus metronidazole for complicated intra-abdominal infections in an era of multidrug resistance: results from a randomized, double-blind, phase 3 trial (ASPECT-cIAI). Clin Infect Dis. 2015;60 (10):1462-1471. doi:10.1093/cid/civ097

35. Armstrong ES, Farrell DJ, Palchak M, Steenbergen JN. In Vitro activity of ceftolozane-tazobactam against anaerobic organisms identified during the ASPECT-cIAI Study. Antimicrob Agents Chemother. 2016;60(1):666-668. doi:10.1128/AAC.01964-15

36. Cho JC, Fiorenza MA, Estrada SJ. Ceftolozane/Tazobactam: a novel cephalosporin/ $\beta$-lactamase inhibitor combination. Pharmacotherapy. 2015;35(7):701-715. doi:10.1002/phar.1609

37. Zhanel GG, Chung P, Adam H, et al. Ceftolozane/tazobactam: a novel cephalosporin/ $\beta$-lactamase inhibitor combination with activity against multidrug-resistant gram-negative bacilli. Drugs. 2014;74 (1):31-51. doi:10.1007/s40265-013-0168-2

38. Miller B, Hershberger E, Benziger D, Trinh M, Friedland I. Pharmacokinetics and safety of intravenous ceftolozane-tazobactam in healthy adult subjects following single and multiple ascending doses. Antimicrob Agents Chemother. 2012;56(6):3086-3091. doi:10.1128/AAC.06349-11
39. Ge Y, Whitehouse MJ, Friedland I, Talbot GH. Pharmacokinetics and safety of CXA-101, a new antipseudomonal cephalosporin, in healthy adult male and female subjects receiving singleand multiple-dose intravenous infusions. Antimicrob Agents Chemother. 2010;54(8):3427-3431. doi:10.1128/AAC.01753-09

40. Xiao AJ, Miller BW, Huntington JA, Nicolau DP. Ceftolozane/tazobactam pharmacokinetic/pharmacodynamic-derived dose justification for phase 3 studies in patients with nosocomial pneumonia. $J$ Clin Pharmacol. 2016;56(1):56-66. doi:10.1002/jcph.566

41. Escolà-Vergé L, Pigrau C, Los-Arcos I, et al. Ceftolozane/tazobactam for the treatment of XDR Pseudomonas aeruginosa infections. Infection. 2018;46(4):461-468. doi:10.1007/s15010-018-1133-5

42. Xiao AJ, Huntington JA, Long J, Caro L. Ceftolozane/tazobactam dose regimens in severely/morbidly obese patients with complicated intra-abdominal infection or complicated urinary tract infection. Int $J$ Antimicrob Agents. 2018;52(3):324-330. doi:10.1016/j. ijantimicag.2018.03.004

43. Kullar R, Wagenlehner FM, Popejoy MW, Long J, Yu B, Goldstein EJC. Does moderate renal impairment affect clinical outcomes in complicated intra-abdominal and complicated urinary tract infections? Analysis of two randomized controlled trials with ceftolozane/tazobactam. J Antimicrob Chemother. 2016;dkw486. doi:10.1093/jac/dkw486

44. Díaz-Cañestro M, Periañez L, Mulet X, et al. Ceftolozane/tazobactam for the treatment of multidrug resistant Pseudomonas aeruginosa: experience from the Balearic Islands. Eur J Clin Microbiol Infect Dis. 2018;37(11):2191-2200. doi:10.1007/ s10096-018-3361-0

45. Crass RL, Rodvold KA, Mueller BA, Pai MP. Renal dosing of antibiotics: are we jumping the gun? Clin Infect Dis. 2018. doi:10.1093/cid/ciy790

46. Alessa MA, Almangour TA, Alhossan A, Alkholief MA, Alhokail M, Tabb DE. Ceftolozane-tazobactam for the treatment of multidrug-resistant Pseudomonas aeruginosa pneumonia in a patient receiving intermittent hemodialysis. Am J Health Syst Pharm. 2018;75(9):e184-e188. doi:10.2146/ajhp170056

47. Oliver WD, Heil EL, Gonzales JP, et al. Ceftolozane-tazobactam pharmacokinetics in a critically ill patient on continuous venovenous hemofiltration. Antimicrob Agents Chemother. 2015;60(3):1899-1901. doi:10.1128/AAC.02608-15

48. Scott LJ. Ceftolozane/tazobactam: a review in complicated intra-abdominal and urinary tract infections. Drugs. 2016;76 (2):231-242. doi:10.1007/s40265-015-0524-5

49. Sherwin R, Winters ME, Vilke GM, Wardi G. Does early and appropriate antibiotic administration improve mortality in emergency department patients with severe sepsis or septic shock? J Emerg Med. 2017;53(4):588-595. doi:10.1016/j.jemermed.2016.12.009

50. Siddiqui S, Razzak J. Early versus late pre-intensive care unit admission broad spectrum antibiotics for severe sepsis in adults. Cochrane Database Syst Rev. 2010;(10):CD007081. doi:10.1002/14651858. CD007081.pub2

51. Dellinger RP, Levy MM, Rhodes A, et al. Surviving sepsis campaign: international guidelines for management of severe sepsis and septic shock: 2012. Crit Care Med. 2013;41(2):580-637. doi:10.1097/ CCM.0b013e31827e83af

52. Martínez ML, Ferrer R, Torrents E, et al. Impact of source control in patients with severe sepsis and septic shock. Crit Care Med. 2017;45 (1):11-19. doi:10.1097/CCM.0000000000002011

53. Stamey TA, Fair WR, Timothy MM, Millar MA, Mihara G, Lowery YC. Serum versus urinary antimicrobial concentrations in cure of urinary-tract infections. $N$ Engl J Med. 1974;291(22): 1159-1163. doi:10.1056/NEJM197411282912204

54. Lee SS, Kim Y, Chung DR. Impact of discordant empirical therapy on outcome of community-acquired bacteremic acute pyelonephritis. $J$ Infect. 2011;62(2):159-164. doi:10.1016/j. jinf.2010.10.009 
55. Yang Y-S, Ku C-H, Lin J-C, et al. Impact of Extended-spectrum $\beta$ lactamase-producing Escherichia coli and Klebsiella pneumoniae on the outcome of community-onset bacteremic urinary tract infections. J Microbiol Immunol Infect. 2010;43(3):194-199. doi:10.1016/S16841182(10)60031-X

56. Spoorenberg V, Hulscher MEJL, Akkermans RP, Prins JM, Geerlings SE. Appropriate antibiotic use for patients with urinary tract infections reduces length of hospital stay. Clin Infect Dis. 2014;58(2):164-169. doi:10.1093/cid/cit688

57. Sartelli M, Malangoni MA, May AK, et al. World Society of Emergency Surgery (WSES) guidelines for management of skin and soft tissue infections. World J Emerg Surg. 2014;9(1):57. doi:10.1186/1749-7922-9-57

58. Sartelli M, Catena F, Ansaloni L, et al. Complicated intra-abdominal infections worldwide: the definitive data of the CIAOW Study. World J Emerg Surg. 2014;9(1):37. doi:10.1186/1749-7922-9-37

59. Joo E-J, Kang C-I, Ha YE, et al. Impact of inappropriate empiric antimicrobial therapy on outcome in Pseudomonas aeruginosa bacteraemia: a stratified analysis according to sites of infection. Infection. 2011;39(4):309-318. doi:10.1007/s15010-011-0124-6

60. Coccolini F, Sartelli M, Catena F, et al. Antibiotic resistance pattern and clinical outcomes in acute cholecystitis: 567 consecutive worldwide patients in a prospective cohort study. Int $J$ Surg. 2015;21:32-37. doi:10.1016/j.ijsu.2015.07.013

61. Castón JJ, De la Torre Á, Ruiz-Camps I, Sorlí ML, Torres V, TorreCisneros J. Salvage therapy with ceftolozane-tazobactam for multidrug-resistant Pseudomonas aeruginosa infections. Antimicrob Agents Chemother. 2017;61(3):e02136-16. doi:10.1128/AAC.02136-16

62. Haidar G, Philips NJ, Shields RK, et al. Ceftolozane-tazobactam for the treatment of multidrug-resistant Pseudomonas aeruginosa Infections: clinical effectiveness and evolution of resistance. Clin Infect Dis. 2017;65(1):110-120. doi:10.1093/cid/cix182

63. Munita JM, Aitken SL, Miller WR, et al. Multicenter evaluation of ceftolozane/tazobactam for serious infections caused by carbapenem-resistant Pseudomonas aeruginosa. Clin Infect Dis. 2017;65(1):158-161. doi:10.1093/cid/cix014
64. Dinh A, Wyplosz B, Kernéis S, et al. Use of ceftolozane/tazobactam as salvage therapy for infections due to extensively drug-resistant Pseudomonas aeruginosa. Int $J$ Antimicrob Agents. 2017;49 (6):782-783. doi:10.1016/j.ijantimicag.2017.04.001

65. Xipell M, Paredes S, Fresco L, et al. Clinical experience with ceftolozane/tazobactam in patients with serious infections due to resistant Pseudomonas aeruginosa. J Glob Antimicrob Resist. 2018;13:165-170. doi:10.1016/j.jgar.2018.01.010

66. Bassetti M, Castaldo N, Cattelan A, et al. Ceftolozane/tazobactam for the treatment of serious P. aeruginosa infections: a multicenter nationwide clinical experience. Int J Antimicrob Agents. 2018. doi:10.1016/ j.ijantimicag.2018.11.001

67. Gallagher JC, Satlin MJ, Elabor A, et al. Ceftolozane-tazobactam for the treatment of multidrug-resistant Pseudomonas aeruginosa infections: a multicenter study. Open Forum Infect Dis. 2018. doi:10.1093/ofid/ ofy 280

68. Wagenlehner FM, Umeh O, Steenbergen J, Yuan G, Darouiche RO. Ceftolozane-tazobactam compared with levofloxacin in the treatment of complicated urinary-tract infections, including pyelonephritis: a randomised, double-blind, phase 3 trial (ASPECT-cUTI). The Lancet. 2015;385(9981):1949-1956. doi:10.1016/S0140-6736(14) 62220-0

69. Popejoy MW, Paterson DL, Cloutier D, et al. Efficacy of ceftolozane/ tazobactam against urinary tract and intra-abdominal infections caused by ESBL-producing Escherichia coli and Klebsiella pneumoniae: a pooled analysis of Phase 3 clinical trials. J Antimicrob Chemother. 2017;72(1):268-272. doi:10.1093/jac/dkw374

70. Drug Safety and Availability - FDA Drug Safety Communication: FDA cautions about dose confusion and medication errors for antibacterial drug Zerbaxa (ceftolozane and tazobactam). Available from: https://www.fda.gov/Drugs/DrugSafety/ucm445919.htm. Accessed February 24, 2019.
Infection and Drug Resistance

\section{Publish your work in this journal}

Infection and Drug Resistance is an international, peer-reviewed openaccess journal that focuses on the optimal treatment of infection (bacterial, fungal and viral) and the development and institution of preventive strategies to minimize the development and spread of resistance. The journal is specifically concerned with the epidemiology of antibiotic resistance and the mechanisms of resistance development and diffusion in both hospitals and the community. The manuscript management system is completely online and includes a very quick and fair peerreview system, which is all easy to use. Visit http://www.dovepress.com/ testimonials.php to read real quotes from published authors. 